\title{
APROXIMACIÓN GNOSEOLÓGICA A LAS DESGRACIAS; UNA REFLEXIÓN SOBRE EL ARTE DIGITAL COMO PRETEXTO PARA HABLAR SOBRE DOS TRABAJOS
}

Sometimes I get overcharged,

that's when you see sparks.

They ask me where the hell I'm going?

At a 1000 feet per second

Por:

"the tourist" Radiohead

\author{
Miguel Tejada \\ Comunicador Social (Universidad del Valle) \\ Especialista en Creación Multimedia (Universidad de los Andes) \\ tejada004@gmail.com
}

\begin{abstract}
Resumen:
En este artículo se reflexiona sobre el estado de la memoria, en medio de la fascinación por el avance tecnológico en las creaciones artísticas digitales, a propósito de dos trabajos para internet realizados por el autor en el año 2009, como parte de sus compromisos académicos en la Especialización en Creación Multimedia de la Universidad de los Andes.

\section{Palabras clave:}

Arte digital, memoria histórica, computación, simulación, idea del tiempo, velocidad, creación, fugacidad, autoinmunidad, terrorismo, Palacio de Cristal, Holocausto del Palacio de Justicia, Catástrofe de Armero, Catástrofes Aéreas, errores informáticos.
\end{abstract}


Ante la desmaterialización de las creaciones artísticas en el espacio electrónico, resultado de su digitalización y la rapidez con que todo esto puede reducirse a ceros, cada vez en menos tiempo, parece que al artista le queda el consuelo del tiempo. Su propio tiempo. Habrá que ver si incluso esta posesión llega a redefinirse en los años que vienen en perjuicio o beneficio de la experiencia del creador, de su ego y su tranquilidad espiritual. Por lo pronto, todavía se necesita de mucha práctica (tiempo, paciencia, estancias prolongadas en mesetas creativas, siempre con el riesgo de fracasar en medio de la abundancia de recursos,) para dominar las técnicas artísticas digitales, y esa posesión le permitirá al artista, durante el tiempo que dure esta certeza, conservar algo de su mística y de su rebeldía, de su encantadora soledad. Solo cuando el tiempo que dedica a sus creaciones ya no le pertenezca, el artista será despojado por fin de todas sus posesiones, de su autoría. Es la relatividad del tiempo actuando como un reto difícil de sobrellevar para la conciencia.

José Luis Brea ${ }^{1}$, crítico de arte, teórico, y fundador de varias revistas de estética y arte visual, decía que la inmaterialidad de los productos artísticos digitales y el modelo de circulación en red cambian la noción de propiedad de la obra de arte. En vez de pasar de una mano a otra (como un objeto material) a cambio de una remuneración económica o un reconocimiento simbólico, la obra de arte en la era de las redes de la información circula sin tener realmente un poseedor. Claro que todavía se debe a un creador que orquesta una puesta en escena y una experiencia, a un planificador de rutas y encuentros perceptuales con distintos grados de significación. Hasta ahora, nada nuevo. Las técnicas artísticas en la creación de arte visual, por ejemplo, conocen la informática hacia los años ochenta. Las creaciones se producían en máquinas paquidérmicas y luego eran sacadas de su confinamiento para ser puestas en circulación en plataformas tradicionales. Hacia mediados de los noventa, la experimentación con la imagen, el videoarte y las simulaciones, empiezan a encontrar soportes digitales capaces de computar acciones y momentos dentro de la máquina ${ }^{2}$. Estamos a poquísimos días de iniciar la era de las redes, y aquí sin duda el análisis del teórico español se sumerge unos metros más en este océano de especulación. El hecho de que el autor de la obra de arte digital (Brea habla de NetArt ${ }^{3}$, concretamente) no sienta un apego especial sobre el objeto de su creación, una obligación paternal (pues ya no hay callos en sus manos y no padece mareos por culpa del penetrante olor del óleo), lo distingue, entre otras razones, del creador del pasado. Pero ahora ocurre algo impensable en tiempos anteriores a la red: la "posesión” del artista, dice Brea, se multiplica ad infinitum a medida que ésta circula por las redes extensas de los escenarios electrónicos. Un sueño hecho realidad. Un "utópico comunismo del conocimiento" Pero esta multiplicación ocurre en tanto la obra es vivida, como una experiencia que se debe al presente o a lo que está por ocurrir.
La obra existe en cientos de miles de puntos sobre la red en tanto circula y se deja conocer a través de la interacción. Esto parece distar de una idea clásica de contemplación y de asombro, de inmovilidad en el flujo impiadoso del tiempo ${ }^{4}$. De la memoria. Este arte que ocurre en tanto se mueve y se transforma es el arte de la corporalidad, de la sinapsis simulada, de la inteligencia artificial.

Pero no se puede perder de vista el fenómeno más grande, que absorbe a la producción artística y la encamina por estos rumbos. Un fenómeno económico global que da origen a una nueva y unificada industria del conocimiento y del entretenimiento. Comprimidos en bits, los nuevos contenidos se llevan de un lado a otro a través de conexiones cada vez más veloces, lumínicas. Hay que pensar en transmisión de datos antes que en almacenamiento, dice Brea. La memoria, el archivo histórico, es un privilegio de coleccionistas que se extingue para dar paso a la interacción, al uso aquí, ahora, al uso virtual (que puede ocurrir, latente, posible).

La situación, por lo menos para plantear un problema de entrada, no parece tan nueva. El autor, superada y enterrada la modernidad como idea de liberación, vuelve a vender su alma, en beneficio de la circulación infinita de su creación. Acepta un lugar dentro del Palacio de Cristal que menciona el filósofo alemán Peter Sloterdijk. Nos tendremos que ocupar pues de seguir el curso de su decisión: ¿sobrevivirá a la banalidad y al Spam? ¿ podrá encontrar puntos de fuga, podrá generar resistencia dentro de esta atmósfera controlada por los grandes mecenas del capitalismo cultural?

2

Esta preocupación acerca del deber ser como individuo es una piedra en el zapato para el acontecimiento de la producción masiva de contenidos culturales. Malestar necesario y siempre bien recibido en claustros académicos y foros intelectuales, porque supone una pausa para reflexionar acerca de la pertinencia de los contenidos, su calidad y su valor como aportes claves para un análisis crítico de los fenómenos sociales. Por lo demás, hay que reconocer que el sustento económico de la mayoría de los árbitros culturales está asegurado, siempre que el hacer artístico no sea su única posibilidad de supervivencia. Los límites están bien definidos, a pesar de las lecturas psicoanalistas que por lo general ridiculizan la cólera del crítico.

Precisamente, la distancia que separa al crítico del artista es parte del gran problema de comunicación (la información abundante en desmedro de un mensaje claro y contundente, de una reflexión ética sobre las consecuencias) al que nos enfrentamos; 
Paso a la acción, pensando hasta dónde me llevan mis ataques de conciencia. Esto me enfrenta rápidamente al reto que la Especialización promueve como un matrimonio encantador, por su rareza y la cantidad de buenos presagios que conlleva. Tengo dos proyectos que servirán para darle alguna esencia real, comprobable, a mis cuestionamientos. Primero, algo relativamente sencillo, por el tema y los medios que debo usar: construir un autorretrato usando elementos multimediales. Claro, tengo que hacerlo solo, sin la simpatía de algún ingeniero. La segunda parte, el proyecto final con el que me hago al título de Especialista en Creación Multimedia, es un trabajo más complejo. Tiene que ser interactivo, dicen los asesores. ¿Y bien, en qué consiste esto de la interactividad?

Para empezar está el ideal democrático, el meter, por las buenas y por las malas, al artista digital en una camisa de fuerza política. Esto no representa, en el papel, una contradicción para mis aspiraciones. Si estoy pensando en generar algún tipo de inquietud con mi trabajo, es obvio que mi deseo está en la misma línea: distribución, discusión, intercambio, y sí, por supuesto, interacción. Pero aquí hay que hacer un alto, digo, porque hablar de interacción en el caso de las obras digitales, de las páginas para internet y de las instalaciones multimediales, no significa introducir un concepto realmente nuevo en la producción artística. La interacción se da cuando usted lee un texto de Dostoievsky ¿No? Déjeme pensar, por un momento, que tengo el privilegio de dialogar con el autor, así éste haya muerto hace tantos años. Claro, no podré obtener respuestas frescas, en tiempo real ¿Pero no actúa mi mente, con sus saberes previos y sus propias construcciones, en tiempo real? ¿no cuestiono o alabo las afirmaciones de este buen Dostoievsky en el mismo momento en que mastico sus palabras, traducidas a mi idioma. No, no tengo intención de negar lo fascinante que podría ser tener al propio autor ruso frente a mí, mirándome incrédulo y sobrador, desafiante o desinteresado. Por supuesto que sería algo maravilloso. Lo que planteamos aquí es una la necesidad de una lectura más amplia del concepto de interacción. Apretar un botón es apenas un gesto mecánico que hace parte de esta nueva forma de hacer posible el intercambio entre un artista y un espectador. Hasta aquí, el enfrentamiento es sano: no estoy condenando la simulación en beneficio de mi romanticismo; estoy tratando de hacer una apropiación menos entusiasta y apresurada de los avances tecnológicos.

El segundo aspecto que surge en la discusión acerca de lo interactivo es el tema del control que tiene el artista sobre su obra. Algo que en últimas se convierte en una preocupación que se desvía de aspectos más esenciales, como la trascendencia y la generación de sentido en procura de una participación menos inconsciente y nihilista frente a algunos problemas que tienen nuestras sociedades. Nadie, en realidad, está obligado a atormentarse por esto. Es una elección ética. Creer en algo o simplemente esperar que los días pasen de la mejor manera posible, sin mirar más allá de la cerca. Los artistas que están generando contenidos en la era de las redes y los soportes digitales ven la pérdida del control como un tema incómodo, porque nadie quiere renunciar a su nombre, nadie, paradójicamente,

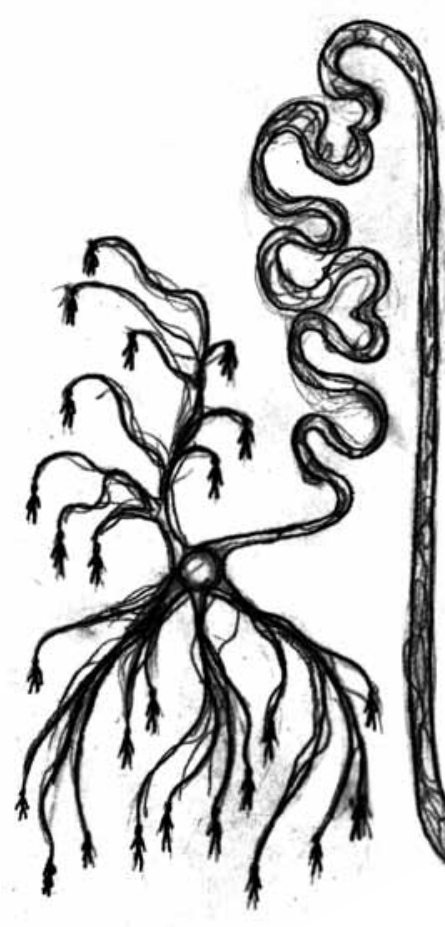

quiere ser borrado de la historia, aún en esta lógica de la circulación y la creación en tiempo real. Por eso, vendrán en adelante más reflexiones acerca de las consecuencias de la interactividad; la hibridación entre biología y arte tecnológico, la inteligencia artificial y la simulación del espacio y el tiempo, y cómo todo esto tiende a desplazar al artista de su posición central como gran arquitecto. Es, como vemos, la segunda fase lo que genera incertidumbre: una vez planteada la creación, el espectador se apropiará de ésta de una forma casi genuina, alejada de la programación básica y predecible.

La respuesta de mis orientadores en el trabajo de grado, a mi pregunta sobre el significado de la palabra interactividad, para el trabajo propuesto (una ficción a propósito del Holocausto del Palacio de justicia y la catástrofe natural en Armero), fue la siguiente: el usuario tiene que enfrentarse a algo dinámico, no lineal, de alguna manera impredecible, interesante, en fin...

5

\section{Primer trabajo: AUTORRETRATO}

\section{Contextualización}

Un avión Boeing 727 de la desaparecida compañía aérea SAM se eleva sobre el océano Atlántico en dirección sur-occidente para cubrir la ruta San Andrés Islas- Cali. Han pasado apenas unos minutos luego del despegue. En la cabina de pasajeros circula, lento y en espirales casi sensuales, el típico aroma del café recalentado. Los niños ya están inquietos y los padres muertos, vencidos por el cansancio. 


\section{¿Por qué los accidentes aéreos?}

Mi madre sujeta con ambas manos los dos apoyabrazos de su asiento. La pobre mujer está experimentando una tensión nerviosa que la inmoviliza, y sí, le da aspecto de cadáver en vida. Yo miro el cielo azul oscuro y sus estrellas, que parecen un set de cine serie B. Mi padre intenta tranquilizar a mi madre acariciándole uno de sus brazos. El hombre hace lo que puede, pero lo que realmente serviría en este caso sería un Xanax o un trago de escocés puro.

Esto ocurre con cierta frecuencia, y no nos privemos de regocijarnos con el fino trazo de la ironía: el avión empieza a sacudirse cuando los pasajeros tienen servidas las bebidas sobre sus mesitas auxiliares, así que tomarse un sorbito de ese café asqueroso se convierte en un número de circo. La voz sensual del piloto sale de los parlantes, explicando los sacudones son una simple turbulencia generada por las corrientes de aire que vienen del Atlántico, bla, bla, bla, y que no se afectará la seguridad del vuelo, etc... Luego nos invita a mirar por nuestras ventanillas la hermosa noche que se abre a medida que al avión se enfila hacia los cielos que reposan sobre el Canal de Panamá. Pero los remezones del pobre aparato empiezan a ser preocupantes, y la gente ya murmura cosas ininteligibles. La señal de abrocharse el cinturón se enciende en todos los puestos y las aeromozas vuelven a sus posiciones.

Tenemos pues la espléndida noche rebosada de estrellas y un solitario Boeing 727 emitiendo estertores metálicos. La posibilidad de que las cosas salgan mal. La gente gritando todos los clichés del fin del mundo. Sin duda su falta de creatividad es más grave que la virtual emergencia aérea.

Este es mi primer encuentro con el caos, y lo estoy disfrutando.

Los compartimientos del equipaje se abren, vomitando todas las porquerías inservibles que los turistas se han traído de la isla. Un tipo calvo y regordete recibe un estéreo en la cabeza. Esto lo noquea instantáneamente. Su mujer llama a las aeromozas, pero éstas ignoran su voz entre tantos gritos y los gruñidos de muerte que salen de las tripas del avión. La voz del piloto (ya menos encantadora) nos dice que tendremos que volver a la isla, porque el avión necesita ser revisado. Acto seguido realiza un viraje brusco que termina por arrojar todas las maletas sobre los pasajeros. Los gritos metálicos de la aeronave son remplazados por un ruido insoportable, como una gran flatulencia que parece el llanto de un inmenso globo desinflándose en pleno vuelo. Mi papá abraza a mi mamá y le pide que se calme, por mi salud mental. Pero en el rostro de mi madre se puede leer que mis días están arruinados, irremediablemente.

Al cabo de un par de minutos el piloto logra poner la aeronave nuevamente en la pista. Hay gente desmayada y defecada. Estamos a salvo, avergonzados. Esta noche también conozco la decepción, y creo que no me agradó.
Dos razones. Una es la recurrencia de un sueño en el que soy un espectador solitario y pasivo de un accidente aéreo; casi siempre estoy parado haciendo nada en algún lugar, y de pronto esta dulce tranquilidad se ve interrumpida por la visión de un avión precipitándose a tierra. A veces, este sueño es bastante verosímil, y en otras ocasiones la emergencia aérea se confunde con un espectáculo de fuegos artificiales o un carnaval del que no tengo la menor idea. Así, lo que me parece curioso es que sea cual sea la versión de este sueño, el sentimiento que me invade es de pura adrenalina. Algo como lo que sientes cuando acabas de conocer al amor de tu vida.

La otra razón es agridulce; o un cariño especial por los errores, tanto en las máquinas como en los humanos. He seguido con bastante morbo relatos sobre accidentes aéreos, y por lo general encuentro detalles interesantes que revelan una relación de amor y odio entre humanos y máquinas. La perfección (lo contrario al error) es un estado de tensión en el que sistemas biológicos y artificiales hacen un conteo regresivo, esperando el instante en que la energía se libere hacia el espacio. Para que cese la tensión. Este es el lienzo donde se pintan los accidentes.

\section{Detalles}

Tuve en mente el concepto de error (glitch ${ }^{9}$ ) en las interfaces y en las transmisiones de datos. Algo que Nam June Paik introdujo como elemento innovador en algunos de sus trabajos de video arte, especialmente el caso de "Global Groove ${ }^{10}$ ", donde revela la fragilidad del proceso de transmisión de la información, pero sin hacer una diatriba panfletaria contra el medio, en este caso la televisión. En una línea conceptual similar, me encuentro el caso del sitio en internet Jodi.org. Interesante no solo por su interfaz críptica y caótica, agresiva visualmente, donde desfilan en la pantalla del computador toda suerte de números y códigos de programación (aparentemente mal escritos) que en un primer momento desconciertan al espectador, pero que contienen un mensaje elaborado (tras bambalinas) bastante contundente: los planos de una bomba de hidrógeno. Otra pieza de jodi.org que me llamó la atención es el enlace en internet ${ }^{11}$ que incuba un error simulado (una broma de mal gusto para cualquier usuario desprevenido de computadoras) en el sistema operativo del ordenador del navegante.

Así fui ensamblando este primer proyecto: mi autorretrato, como una pila de enlaces en internet cuya fachada es una representación plana de un paisaje (hecho en código HTML y estilos CSS) donde aparecen una torre de control aéreo y el ícono de un avión comercial. Todo esto viene acompañado del sonido de una conversación entre controladores aéreos y los pilotos de una aeronave cualquiera $^{12}$. Los enlaces llevarán entonces a una serie de informaciones que aparecerán siempre acompañadas por elementos multimediales, como videos, imágenes, animaciones y audios de accidentes aéreos. 
La elaboración de este trabajo me obligó a imponerme reflexiones respecto al proceso de creación de productos para internet. Digamos que en este primer momento pienso en el debate acerca del nivel de comunión que los nuevos artistas tienen con los dispositivos tecnológicos. Por supuesto, estoy pensando en las consecuencias.

Mi formación profesional de base, para empezar, muy poco tuvo que ver con este despliegue tecnológico que se expande a una velocidad difícil de contener, y que cada vez gana más terreno en el campo artístico. Si bien estoy en paz con muchos elementos recibidos en mi paso por la academia (nociones filosóficas, sociológicas, históricas y literarias), hoy encuentro que el hecho de haber pospuesto la preocupación acerca de la inminencia de esta nueva historia que se está empezando a escribir evidencia un enfoque todavía miope en algunas escuelas universitarias.

Esto, para el caso de la Universidad de los Andes, ha sido un proceso de ida y vuelta. Para la muestra, la creadora del programa de Especialización en Creación Multimedia es una ingeniera de Sistemas; un ejemplo muy claro de que no solo se trata de sugerirle a los artistas que se animen a pensar en la creación con las herramientas digitales, sino que las mismas personas de ciencia podrían involucrarse de manera directa con la enseñanza y la investigación en arte, como el caso de la profesora.

Con todo, por los giros que se presentan en el destino profesional de las personas, empecé por mi cuenta a conjugar mis saberes académicos y mis impulsos artísticos - mi gusto por la literatura y la ilustración-, en el escenario electrónico. Esto me deja hasta el momento un sabor agridulce. Por un lado está la inseguridad respecto a mi conocimiento histórico de las técnicas artísticas; el respeto por un oficio. No me quedan dudas respecto a la maravillosa eficiencia y verosimilitud que un programa como Photoshop me puede ofrecer; puedo ver la textura simulada del óleo, impregnar de aceite mi pantalla...pero por alguna razón, todo huele a ese perfume tan esquivo y difícil de distinguir en muchas ocasiones: fraude.

Luego está mi urgencia por sacar estos contenidos artísticos de la red (o bien darles otra dinámica); aunque más que exhibirlos para construir un portafolio, siento la necesidad de dejarlos flotando en el espacio, como un trozo de mi memoria. Siempre disponible, intacta. Es una invitación a ver, con muy buenos ojos, la gran ventaja que tiene la inmaterialidad de esta tecnología. Las fotos en papel se envejecen y se hacen polvo, las cintas de audio y video se deshacen, pero esto que existe y no existe, que está aquí y luego, con un gesto sencillo, está acá o allá, mil, cien mil o un millón de veces, multiplicado tantas veces como alcance a desearlo. Es una reiteración, lo que acabo de decir, pero es necesaria: hay que hacer memoria con estas teconologías.
Respecto al contenido en sí del trabajo, empiezo hablando de lo que pudo haberme inspirado: por un lado, pongo en un lugar privilegiado la obra de Samuel Beckett, en tanto evidencia y denuncia de la vaciedad y el carácter estático que pueden adoptar los discursos convencionales, es decir, la vida misma que los individuos construyen con sus palabras. Es claro que Beckett no renuncia en su obra literaria y en su dramaturgia a la generación de sentido. Esto explica porqué la etiqueta de absurdo nunca fue del todo bien recibida por el autor, ya que en muchos casos ésta se utilizaba en un sentido muy superficial.Y de eso no se trata.

La disposición de mis recuerdos, articulados con un tema de fondo, parece un gesto torpe y precario en su estética (el hecho de que luzca como una página hecha a principios de los noventa), un listado soso y esquizofrénico de imágenes, de asociaciones; pero ahí está la vida, condensada en códigos informáticos, con un plano de fondo: una catástrofe aérea. El paso de la felicidad al terror en cuestión de segundos.

Volvía una y otra vez, mientras elaboraba este trabajo, a la discusión en clase: la elaboración de obras digitales para fines comerciales o para combatir la vaciedad. Parece imprescindible, en la opción comercial, trabajar con códigos comunicativos y con estereotipos que circulan en el espacio social; como si no existiera otra manera de llegar al público. Aquí el arte claramente cede lugar a la lógica de mercado, pero este proceso se hace de manera silenciosa y en muchos casos ilusoria. Esto trae consecuencias paradójicas para ambas partes: el mercado reclama innovación, ingenio y dinamismo, y el arte concede en la mayoría de los casos piezas geniales para fines netamente comerciales. Aquí, la línea que separa un campo del otro se desvanece. La publicidad también puede permitir en muchos casos la irrupción de obras de gran factura que conservan elementos caprichosos desde el punto de vista artístico ${ }^{13}$, pero esta relación difícilmente llegará a ser un matrimonio estable, porque se trata más o menos de dos entelequias casadas cada una con una religión, y como pasa en muchos casos, cuando llega la hora de la verdad, una de las dos debe renunciar a su fe. Por supuesto, es el mercado el que casi nunca está dispuesto a abandonar sus principios.

\section{El uso crítico de las tecnologías para pensar el arte}

En el caso de Beckett, sus textos narrativos, su dramaturgia, sus obras radiofónicas y televisivas, y su tímida incursión en algunos proyectos fílmicos, son una muestra suficiente para respaldar toda una corriente de artistas que buscan llegar con sus obras a lugares apartados y empolvados en la mente del espectador. Algo similar, para hablar solo de un par de casos, podemos ver en la obra de David Lynch, con toda su carga psicológica que no busca otra cosa que hablar de situaciones ordinarias, pero 
desnudando en éstas la complejidad de la mente humana. En este mismo campo, el movimiento Dogma, cuya cabeza más visible es el director danés Lars von Trier, ilustra la apropiación de los medios tecnológicos para darle fuerza a un discurso, a una propuesta. En este caso, los principios del Dogma 95 quieren hacerle saber al espectador que sobre los elementos técnicos del cine deben prevalecer las situaciones dramáticas. Esto puede interpretarse entonces como una manera de reflejar en la pantalla lo poco clara (iluminada) que resulta en muchas ocasiones la propia realidad; es una afirmación que cuestiona principalmente el enfoque comercial y obvio de Hollywood.

Gran parte de mi interés en la discusión sobre la creación multimedial se centra en la necesidad de consolidar en el proceso de creación con técnicas digitales conceptos que sustituyan aquella sensación de mega producción desconcertante, abundante y caótica. Abogo por la consolidación de reflexiones permanentes acerca de la facilidad que tiene el artista para expresarse en estos tiempos; es decir, pensar en el talento artístico (y en la abundancia de herramientas y posibilidades de creación ${ }^{14}$ ) como un conjunto de bienes que deben ser devueltos a la sociedad de manera eficaz; esto se lograría entonces generando propuestas trascendentales en un sentido netamente social. .Eduardo $\mathrm{Kac}^{15}$ habla de crear nuevas realidades a partir del arte digital; de abandonar las simulaciones y pensar en propuestas que abran campo a un nuevo movimiento de reflexión sobre la experiencia humana.

\section{Lo interactivo y la trascendental}

Hay que pensar en una nueva etapa en la que el protagonismo del espectador se transforme de manera significativa. Hasta aquí, esta afirmación podría hacer parte de un discurso cliché sobre la situación de los consumidores de medios; el televidente y el espectador de cine en la actualidad, parecen ser algo distinto al espectador de hace 60 ó 50 años, pero si miramos bien, no encontramos grandes diferencias de fondo, salvo la compulsión del consumidor actual de contenidos. Esto obedece a la lógica comercial que ha logrado colarse en el campo artístico; la pose hedonista del individuo contemporáneo es una respuesta a la extenuante dinámica laboral, y este cansancio es aprovechado por productores y agentes que se encargan de crear productos artísticos y piezas de entretenimiento que perpetúan este cansancio, que refuerzan el desinterés y la condena a no levantarse nunca más de la silla. Entonces, la esperanza con las posibilidades del arte digital se reducen a una cosa: estamos hablando de un medio relativamente nuevo, que esconde rincones y fronteras, y por ahí, a lo mejor, se puede crear algún foco de resistencia al cáncer comercial, a la generación de obras chatarra que acaban con cualquier impulso genuino vital.

Con todo, pienso que el debate debe ir más allá del análisis rabioso que condena la supuesta pasividad del espectador que consume medios o piezas artísticas comerciales. La experiencia virtual, la generación de sentido a través de interfaces y apli- caciones, está basada en expectativas que tienen origen en la vida real. Esto evidencia entonces que la mente del espectador no está apaciguada, sino que está respondiendo a una realidad en la que se le facilita hacer versiones previas (previews) de lo que puede pasar por fuera de una comunidad virtual. De todas formas, es claro que esta situación necesita un acompañamiento constante por parte de los artistas y los teóricos del arte y los medios de comunicación, sobre todo porque es bastante probable que la dimensión material de estas experiencias virtuales (entiéndase aquí lo material como el uso frenético de dispositivos y aplicaciones on line) opaque por momentos la dimensión humana y la dimensión espiritual; es decir, la trascendencia de las piezas artísticas interactivas. La simulación no debe ser entonces condenada, sino replanteada, porque se trata en realidad de prever las posibilidades que ésta nos confiere para entendernos como seres humanos dotados de capacidades intelectuales y poseedores de una cualidad que las invenciones tecnológicas nunca podrán alcanzar.

Un reto interesante para los artistas contemporáneos consistirá en pensar el arte interactivo como algo capaz de romper categorías creadas por el marketing, por ejemplo, la segmentación de públicos. Es muy probable que el caso del conejo Alba ${ }^{16}$ de Eduardo Kac resulte interesante no solo para aquellos círculos relacionados directamente con los debates éticos en el campo científico. Kac provoca con su obra una reacción que debe resultar pertinente incluso en escenarios educativos básicos e iniciales, como la escuela primaria o secundaria: la relación del hombre con la naturaleza y la tecnología ha sido siempre compleja; la historia de las culturas y sus explicaciones de los elementos del entorno es una gran caja de sorpresas, donde nada es como parece, o como nos lo han querido mostrar.

Por esto, no parece descabellado, por ejemplo, pensar en un remake multimedial de Eleutheria ${ }^{17}$, una de las obras teatrales de Samuel Beckett; pensando sobre todo en públicos en teoría completamente ajenos al mundo teatral. Por un lado, pienso que Victor Krapp, el personaje en cuestión en la obra, bien puede presentarse como un adolescente atribulado que exige respuestas categóricas de los suyos, cuando en realidad es esto lo que menos importa en su trance. Ver representada con elementos actuales esta posición de un ser humano frente a la existencia también puede acercarnos a un escenario en el que las categorías y las clasificaciones buscan principalmente encasillar a los individuos en usos y rutinas que se definen y se legitiman por lo general sobre una base materialista y reduccionista, lo cual termina imponiendo cortapisas a la necesidad de encontrar una verdadera trascendencia de la experiencia humana.

Enlace para conocer el proyecto Autorretrato:

http://proyectosic.com/autorretrato_migueltejada/ 
Segundo proyecto:

"Gracias a Dios por este desastre natural"

El acontecimiento no admite la mirada retrospectiva. Es una sentencia bíblica. Una avalancha de lodo y rocas volcánicas sepultando un pueblo del Tolima en 1985 es algo mil veces más grande que la curiosidad. Llega de golpe y así se lee, en un solo momento. El que mire hacia atrás, donde reposan humeante el esqueleto calcinado del Palacio de Justicia, quedará convertido en estatua de sal.

Esto es una novela que tal vez nunca conozca un final, porque cada vez que intento concebir un desenlace único, absoluto, como un punto negro sobre la nada, entiendo que el verdadero sentido de los temas que decidí abordar es algo que me sobrevivirá. Usted y yo, lector, moriremos antes de que todo se componga, porque, sencillamente, tal vez las cosas no estén así de mal. El caos sería pensar lo contrario. Nosotros vendríamos a ser los estorbos antinaturales, la materia inútil que cayó de algún lado, pero que desaparecerá en el tiempo.

Esto es un libro como el que siempre quise leer. No hay trucos, no hay conspiraciones para controlar su pensamiento o crearle nuevos hábitos de lectura; esta es mi lectura de la realidad, y la comparto con usted. Espero, eso sí, que pueda reflexionar un poco sobre los siguientes aspectos:

-Antes no sufríamos de rinitis. Hoy no podemos abrir un libro sin estornudar.

-Antes leíamos en la oscuridad, acompañados solo por la luz de una vela. Hoy la luz de las pantallas LCD enrojece nuestros globos oculares.

-Antes podíamos concentrarnos tanto en algo, que en ocasiones sudábamos sangre. Hoy practicamos algo

llamado procastinación. Abarcar, mucho, apretar, poco.

-Antes pasábamos horas en silencio reflexionando, hoy no decimos nada, pero hacemos parte de comunidades virtuales para estar en contacto con la gente.

\section{¿Por qué?}

El único asunto del debate político que suelo tomarme en serio es el trato que se le da al sentido común. Aún no he escuchado al primer político que hable con la verdad. Tengo casi 30 años, peso 76 kilos y he estado enamorado dos veces. Eso dice algo de mí: soy un cualquiera. Y por eso, lo único que reclamo, con furia, es respeto por el sentido común. De cosas más banales o más elevadas uno se puede ocupar en otros espacios, en otros escenarios, pero del sentido común no puede uno escapar, nunca. Por eso, a veces sueño que soy un político chiflado que habla con la verdad. Algunas personas me odian, me tiran tomates

podridos y esconden a los niños cuando salgo en televisión, otras personas me aman y consideran que soy Dios, o en su defecto el hijo alocado de éste. Soy famoso. Todos hablan de mí, y esta fama me la he ganado diciendo la verdad, cruda, cortante, explosiva.

El título de este trabajo es la frase espontánea y honesta que nunca se dijo cuando se empezaron a conocer las cifras reales de la tragedia de aquel pobre pueblo del Tolima que terminó sepultado bajo toneladas de lodo y rocas. Lodo y rocas. El escenario político se compuso. Todo el mundo estaba pensando en la tragedia, porque la mayoría de nosotros somos perezosos y egoístas, y cuando el sentido común nos suplica que le prestemos atención, le damos la espalda, bostezamos o vemos un partido de fútbol.

Todo empezó con una imagen que se repite en mi cabeza: en la plaza de Bolívar de Bogotá hay un anciano que vende baratijas. A su alrededor hay decenas de personas protestando; son los familiares de los desaparecidos en el holocausto del Palacio de Justicia, y bien, es eso lo que están exigiendo: justicia. Los agentes de la fuerza pública que cuidan la escena en la plaza rodean al anciano. Cuando se acercan a él, descubren que entre todas las cosas que lleva en su pequeño carro de baratijas hay unos soldados de plástico. La reacción de los uniformados es exagerada: forcejean con el anciano y lo obligan a marcharse. Es evidente que se toman a pecho el detalle de los soldados de plástico. El anciano opone resistencia durante un par de minutos, pero luego se rinde, dejando todo en manos de la providencia. 
Esta es la sinopsis de la ficción que dio origen a este proyecto multimedial. El título es una afirmación irónica que tiene como objetivo subrayar la desafortunada convergencia de fanatismo religioso y la inexistencia de un Estado que garantice, sobre cualquier cosa, el bienestar de sus ciudadanos, y las consecuencias culturales (folclóricas) de todo esto: el sentido común y la capacidad de analizar racionalmente las cosas es desplazado por el adormecimiento, el olvido y la distracción banal. Colombia es un país de apariciones virginales, de partidos de fútbol de pésimo nivel deportivo, de reinados de belleza y de telenovelas.

La idea inicial era realizar una animación con esta historia, pero luego terminé concibiendo proyecto más complejo: un texto literario multimedial que podría definirse como una micronovela electrónica dividida en dos grandes capítulos: la primera parte tendrá como eje estético la técnica del file footage. Aquí el lector/navegante de la obra encontrará una serie de historias acompañadas de videos, fotos fijas o sonidos, todos relacionados con los dos hechos históricos que sostienen todo el proyecto: la toma del Palacio de Justicia y la tragedia de Armero. Así, mediante el lenguaje literario, me propongo de manera libre sentar mi punto de vista sobre la realidad de este acontecimiento. Pero lo que más me interesa señalar es el estado en el que queda esta trabajo, y no se me ocurre nada mejor para explicar lo que intento decir usando la figura de la maqueta. Detenidas en el tiempo, finalizada en algún momento, y luego entregada en una caja de cristal, exhibida durante un tiempo indefinido, para que los espectadores puedan ver, en un solo momento, el pasado, el presente y el futuro. Así, este documento que reúne elementos históricos de dos hechos importantes para la historia este país, se congela en las pantallas del espacio electrónico, como una visión titilante y estática del pasado, pero presente, disponible en cualquier momento.

Enlace para conocer el trabajo: http: / / proyectosic.com/gd/

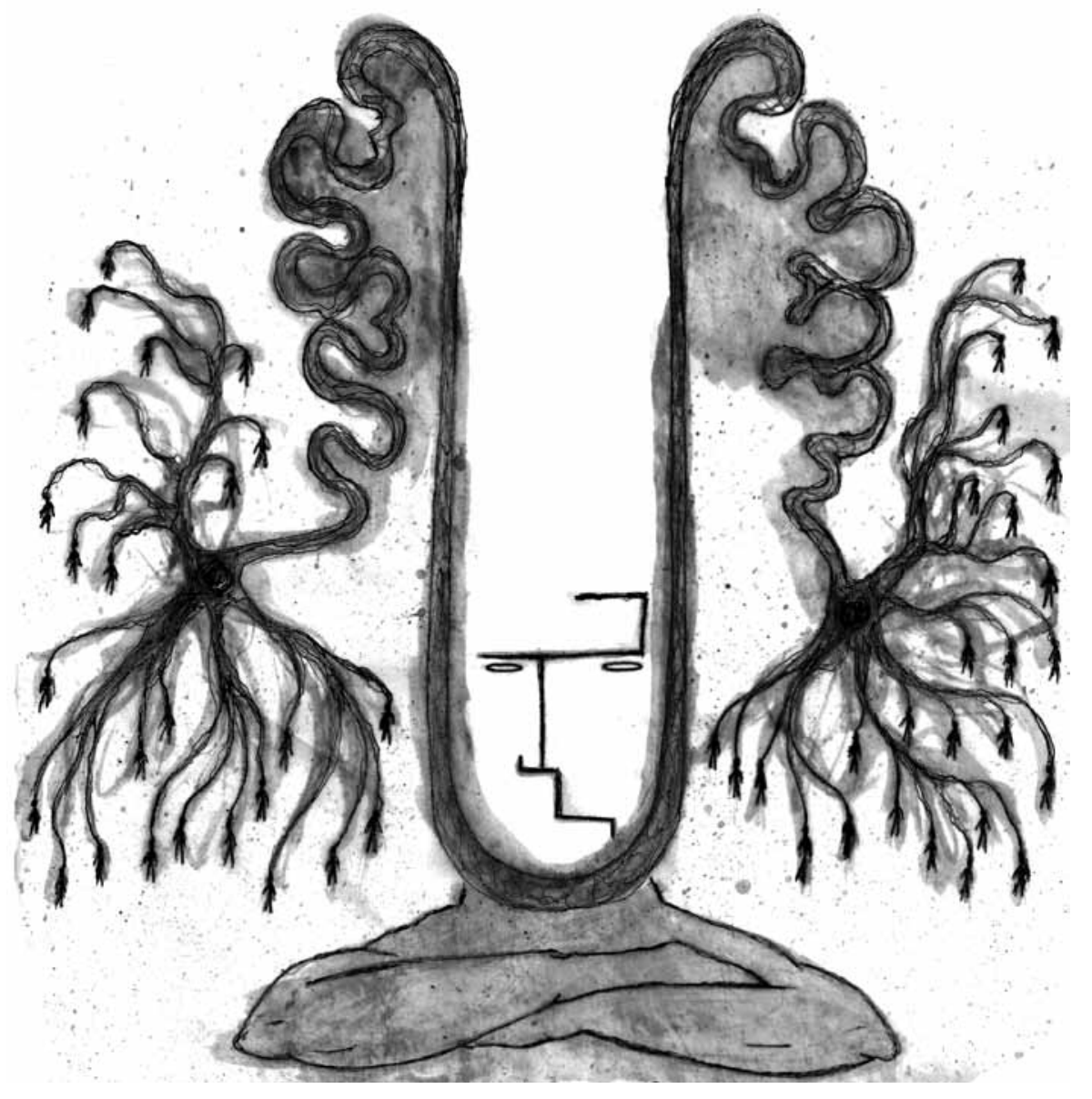

Agradecimientos:

Miguel Camacho Marcos Camacho María Juliana Soto. N. Felipe Muñoz. J. Gerald Bermúdez Manuel Hernández. B. Luis Alberto Mejía Clavijo 
1. 1957-2010) Fue profesor titular de Estética y Teoría del arte contemporáneo en la Universidad Carlos III de Madrid. Director de las revistas Estudios Visuales y ::salonKritik::. Crítico de arte independiente, colaboró con diversas revistas nacionales e internacionales. Dirigió también la colección Estudios Visuales de la editorial AKAL.

${ }^{2 .}$ Lucía Santaella "El arte del Silicio". Texto publicado en El medio es el diseño audiovisual, La Ferla Jorge (comp.), Universidad de Caldas, Manizales, 2007.En portugués en la revista Cybercultura del Centro Cultural del Banco Itaú, San Pablo, Brasil, 2003 www.itaucultural.org.br/index.cfm? cd pagina $=2014 \& \mathrm{~cd}$ materia $=458$

${ }^{3 .}$ Del texto "El net.art y la cultura que viene", publicado en el libro El Tercer Umbral. Estatuto de las prácticas artísticas en la era del capitalismo cultural. Centro de Documentación y Estudios Avanzados de Arte Contemporáneo, CendeaC, Murcia, España, 2004.

4. La inmortalidad está relacionada con la inmovilidad, con la exposición de una imagen congelada en el tiempo, a salvo de la velocidad y el cambio frenético, eternizada. Al morir, el hombre se vuelve visible.

5. SLOTERDIJK, Peter, "El Palacio de Cristal", Conferencia pronunciada en el marco del debate "Traumas urbanos; La ciudad y los desastres", Centro de Cultura Contemporánea de Barcelona, CCCB. 2004. www.cccb.org/rcs_gene/petersloterdijk.pdf

6. Manuel Hernández, "Plano secuencia: más medios ¿menos comunicación” Revista Clave $\mathrm{N}^{\circ} 2$, Departamento de Artes, Universidad de Los Andes, Bogotá, 2009

7. SLOTERDIJK, Peter, "El Palacio de Cristal" Conferencia pronunciada en el marco del debate "Traumas urbanos; La ciudad y los desastres", Centro de Cultura Contemporánea de Barcelona, CCCB. 2004. www.cccb.org/rcs_gene/petersloterdijk.pdf

${ }^{8}$ Entrevista de Giovanna Borradori con Jacques Derrida el 22 de octubre de 2001 en New York. Traducido del francés por: J Botero en «La filosofía en una época de terror. Diálogos con Jürgen Habermas y Jacques Derrida» Taurus, Buenos Aires, 2004

9. “Glitch Studies Manifesto.” http: / /www.slideshare.net/r00s/glitch-studies-manifesto

${ }^{10 .}$ http: / /www.medienkunstnetz.de/works/global-grove/

${ }^{11 .}$ http: / / oss.jodi.org/ | Una “deconstruccion” de la interfaz de usuario de Windows y Mac OS 9-

${ }^{12 .}$ Bajados de internet, You Tube. Después, el audio es extraído con ayuda de un software.

13. Un ejemplo de este caso pueden ser los comerciales televisivos de la aerolínea Air France o algunos de la marca de jeans Levi's. En ambos casos podemos ver que artistas como Michel Gondry han "metido la mano" para generar piezas publicitarias que han ganado numerosos reconocimientos. $\mathrm{Y}$ aunque de esto no se hable mucho, estos premios han reconocido de manera indirecta que tales piezas parecen todo menos comerciales de televisión:

http: / / www.youtube.com/watch?v=Uj6G1C6c0uw

http: / / www.youtube.com/watch?v $=$ VmNztYfInOA\&feature $=$ related 
14. Para Eduardo Kac, lo digital ha alcanzado su límite, su culminación como revolución; lo que sigue, en adelante, serán solamente extensiones de esto. Por eso insiste en la necesidad de pensar en una trascendencia real de lo que se genere en el campo digital.

Ver: http://www.ekac.org/elmundo2001.html

15. Artista brasilero reconocido internacionalmente por sus instalaciones interactivas y por sus trabajos de bio arte. En el año 2000 adquirió fama mundial por la creación de Alba, un conejo fluorescente que servió como catalizador del debate global sobre la ingeniería genética. El proyecto "GFP Bunny” logró generar una gran cantidad de discursos críticos acerca de los aspectos legales, éticos o estéticos del arte, la ciencia y la sociedad en relación con los desarrollos de la tecnología genética. Fragmento tomado de : http://www.ekac.org/

16. http://www.ekac.org/gfpbunny.html\#gfpbunnyanchor

17. http://en.wikipedia.org/wiki/Eleutheria_\%28play\%29

\section{Bibliografía}

Ascott, Roy "La Trayectoria del Arte: Medios-húmedos y las Tecnologías de la Conciencia” Publicado en Artes y Medios Audiovisuales. Un estado de situación, Nueva Librería, Buenos Aires, 2007; El medio es el diseño audiovisual, Universidad de Caldas, Manizales, 2007.

Beckett, Samuel, “Eleutheria”Tusquets Editores. Barcelona, 1996.

Brea, José Luis, "El net.art y la cultura que viene”, publicado en el libro "El Tercer Umbral. Estatuto de las prácticas artísticas en la era del capitalismo cultural”. Centro de Documentación y Estudios Avanzados deArte Contemporáneo, CendeaC, Murcia, España, 2004.

Cantoni, Rejane "Máquinas de pensar/Máquinas de pensamiento "Publicado en El medio es el diseño visual, Universidad de Caldas, Manizales, 2007.

Derrida, Jacques, "La filosofía en una época de terror. Diálogos con Jürgen Habermas y Jacques Derrida” Taurus, Buenos Aires, 2004

Hernández García, Iliana, "Mundos virtuales habitados: Espacios electrónicos interactivos". Centro Editorial Javeriano, CEJA . Bogotá, 2003.

Hernández Benavides, Manuel, "Plano secuencia: más medios ¿menos comunicación” Revista Clave N² 2, Departamento de Artes, Universidad de Los Andes, Bogotá, 2009.

Machado, Arlindo, "El advenimiento de los medios interactivos" (Publicado en El medio es el diseño audiovisual, Universidad de Caldas, Manizales, 2008 y en El paisaje Mediático. Sobre el desafío de las poéticas tecnológicas, Arindo Machado, Libros del Rojas, Buenos Aires, 2000.)

Manovich, Lev, “¿Qué son los “Nuevos Medios”? Publicado en El lenguaje de los Nuevos Medios de Comunicación, Paidós, Buenos Aires, 2006.

Santaella, Lucía "El arte del Silicio". Texto publicado en El medio es el diseño audiovisual, La Ferla Jorge (comp.), Universidad de Caldas, Manizales, 2007.

SLOTERDIJK, Peter, "El Palacio de Cristal”, Conferencia pronunciada en el marco del debate "Traumas urbanos; La ciudad y los desastres”, Centro de Cultura Contemporánea de Barcelona, CCCB. 2004. www.cccb.org/rcs_gene/petersloterdijk.pdf

SLOTERDIJK, Peter, "Esferas II. Globos. Macrosferología. Ediciones Siruela. Madrid, 2004.

Virilio, Paul, "El arte del motor. Aceleración y realidad virtual” Ediciones Manantial. Buenos Aires, 1996. 